\title{
Cholecystoduodnal Fistula-Gallstones Finds their Way
}

\section{Rana L ${ }^{1 *}$, Gupta $S^{2}$, Gurnal $P^{3}$, Negi $P^{1}$, Sharma $A^{1}$ and Rangani $S^{1}$}

${ }^{1}$ Department of Radio-diagnosis, Dr RPGMC Kangra at Tanda, India

${ }^{2}$ Department of Gastro-enterology, Dr RPGMC Kangra at Tanda, India

${ }^{3}$ Department of Anaesthesia, Dr DRPGMC Kangra at Tanda, India

*Corresponding author: Lokesh Rana, Department of Radio-diagnosis, Dr RPGMC Kangra at Tanda, Himachal Pradesh, India, Email: poojalokesh2007@gmail.com

\section{Case Report \\ Volume 3 Issue 1}

Received Date: December 26, 2019

Published Date: February 10, 2020

DOI: $10.23880 /$ ijnmrs-16000121

\section{Abstract}

We present a case of 40 year female who was diagnosed with cholelithiasis few years back but was managed conservatively and on CECT after 10 year shows presence of cholecysto-duodnal fistula.

Keywords: Cholecystoduodnal Fistula; Chronic Cholecystitis; Bouveret syndromes; Hepaticojejunostomy

\section{Case Report}

A 40 year old female with history of gall stone for 12 years and pain epigastrium for 2 months. She has history of similar complaints few year back in 2009, which was recurrent in nature in particular after taking fatty meals, Got her USG done and was diagnosed with cholelitiasis which was also largely ignored and got relief from injectable pain subsides, and the pain subsided after 3-4 recurrences within in period of 6 months. Again in 2019 she presensented with pain epigastrium but less severe in nature then earlier. CECT was done and images showing fistulous communication between 2nd part of duodenum and gallbladder though not clearly demonstrated, gallbladder is contracted and contains air in its lumen. Features are suggestive of cholecystoduodnal fistula and chronic cholecystitis.

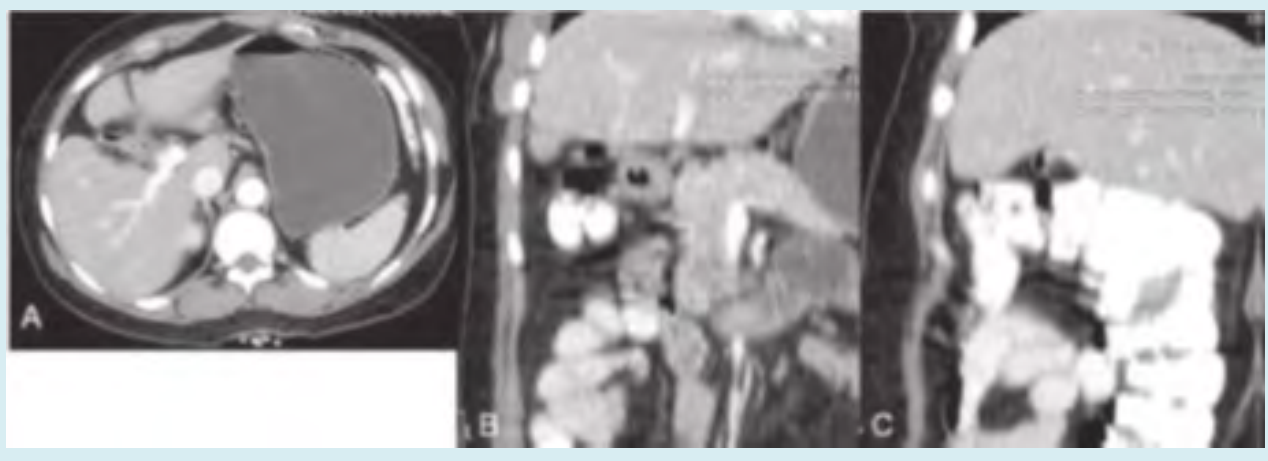

Figure 1: CECT images(A, B and C) of 40 year old female with history of cholelithiasis showing fistulous communication between 2nd part of duodenum and gallbladder though not clearly demonstrated, gallbladder is contracted and contains air in its lumen. Features are suggestive of cholecystoduodnal fistula and chronic cholecystitis. 


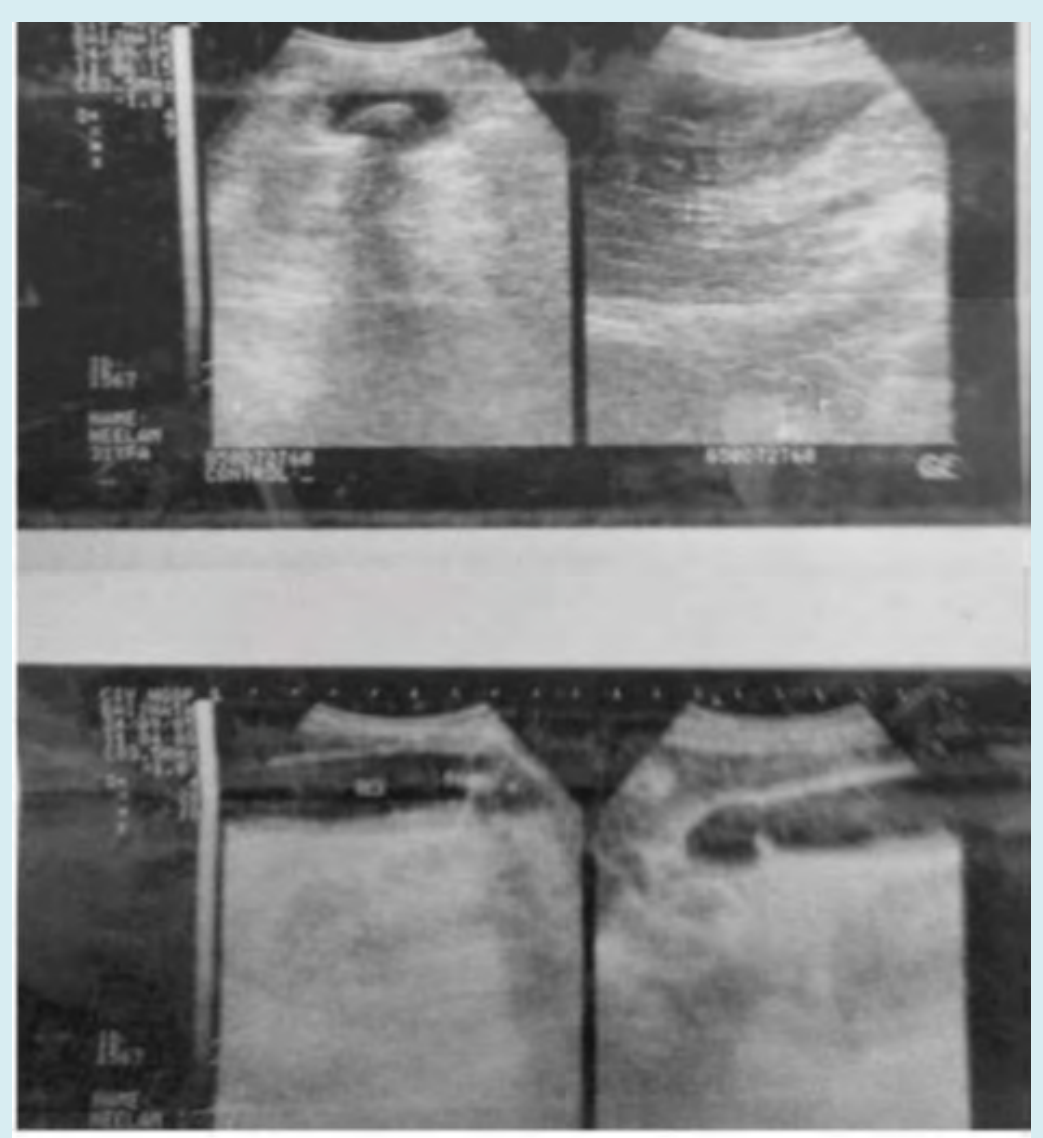

Figure 2: USG which was done 5 year back shows presence of calculus of size $9 \mathrm{~mm}$ with posterior acoustic shadowing.

\section{Discussion}

Cholecystoduodnal fistula is fistulous communication between gall bladder and duodenum. It is mostly secondary to gallstones which migrate to the duodenum [1,2]. It may be is some cases iatrogenic in origin, especially after sphincterotomy and after hepaticojejunostomy or choledochojejunostomy [3-5]. Although patients may be asymptomatic, possible complications include gallstone ileus, Bouveret syndrome or recurrent episodes of cholangitis. It has variable clinical presentation is there, it can be asymptomatic or may present with bouveret syndrome [6].

Enterobiliary fistula was first described by Bartholin in 1654. Sixty-eight per cent of cases occur between the gallbladder wall and duodenum and may cause gallstone ileus and Bouveret syndromes [7].

The key imaging diagnostic clues are

- Direct visualisation of the tract may be seen in some cases

- Air in the gallbladder with collapsed contracted gallbladder and

- Gallstone seen in previous scans are absent without history of any surgical intervention $[8,9]$.

\section{Conclusion}

In patients with peptic ulcer disease and history of previous imaging suggesting cholelitihiasis while in present scan having no evidence of gall stones, one must consider the presence of a proximal choledochoduodenal fistula. Patients with recurrent episodes of cholangitis should be investigated for a distal choledochoduodenal fistula. A high index of suspicion is needed from radiologist too for this relatively difficult condition to diagnose $[10,11]$.

\section{References}

1. Stagnitti F, Mongardini M, Schillaci F, Dall'Olio D, Pascalis MD, et al. (2000) Spontaneous biliodigestive fistulae. The clinical consideration, surgical treatment and complications. G Chir 21(3): 110-117.

2. Xeropotamos NS, Nousias VE, Vekris AD, Katsanos KH, Tsianos EV, et al. (2004) Choledochoduodenal fistula: an unusual complication of penetrated duodenal ulcer disease. Ann Gastroenterol 17(1): 104-108. 


\section{International Journal of Nuclear Medicine \& Radioactive Substances}

3. Eliason EL, Stevens LW (1941) Spontaneous internal biliary fistulae. Am J Surg 51(2): 387.

4. Adam A, Dixon AK, Gillard JH, Schaefer-Prokop C, Grainger RG, et al. (2014) Grainger \& Allison's Diagnostic Radiology E-Book. Elsevier Health Sciences.

5. Haaga JR, Boll D Computed Tomography \& Magnetic Resonance Imaging of the Whole Body E-Book-003, 180(4): 1033-1035.

6. Kyle J (1958) Choledochoduodenal fistula due to duodenal ulceration. Br J Surg 46(196): 124-127.

7. Hoppenstein JM, Medoza CB, Watne AL (1971) Choledochoduodenal fistula due to perforating duodenal ulcer disease. Ann Surg 173(1): 145-147.
8. Negi RS, Chandra M, Kapur R (2015) Bouveret syndrome: Primary demonstration of cholecystoduodenal fistula on MR and MRCP study. Indian J Radiol Imaging 25(1): 3134.

9. Pickhardt PJ, Friedland JA, Hruza DS, Fisher AJ (2003) CT, MR cholangiopancreatography, and endoscopy findings in Bouveret's syndrome. American Journal of Roentgenology 180(4): 1033-1035.

10. Butler P, Mitchell AW, Ellis H (1999) Applied radiological anatomy. Cambridge University Press.

11. Sutton D (2003) Text Book of Radiology and Imaging. Churchill Livingstone, London, 2: 1453-1487. 